\title{
Different Signals Control Laminar Specificity of Commissural and Entorhinal Fibers to the Dentate Gyrus
}

\author{
Shanting Zhao, ${ }^{*}$ Eckart Förster, ${ }^{\star}$ Xuejun Chai, and Michael Frotscher \\ Institute of Anatomy, University of Freiburg, D-79001 Freiburg, Germany
}

The factors governing the characteristic laminated termination of hippocampal afferents are essentially unknown. Principally, diffusible factors of the target region, membrane-bound molecules on the ingrowing afferent fibers and on the postsynaptic target cells as well as molecules of the extracellular matrix (ECM), may play a role. Using slice cocultures as a model, we show that hyaluronic acid, an ECM molecule, is essential for the segregated, layer-specific termination of entorhinal fibers but not of commissural afferents to the mouse dentate gyrus. Laminar specificity of the latter, in contrast, is determined by the position of the postsynaptic granule cells. Thus, malpositioning of the granule cells in slice cultures from reeler mutant mice altered the projection of commissural fibers from cocultured wild-type hippocampus. In contrast, commissural fibers from reeler mouse hippocampus formed a normal, sharply delineated projection to the inner molecular layer of cocultured wild-type dentate gyrus, precluding a cell-autonomous effect of the reeler mutation on commissural neurons. Interestingly enough, entorhinal fibers formed their normal, sharply delineated projection in cocultured reeler dentate gyrus despite the malpositioning of the target granule cells. Because hyaluronan-associated molecules are likely to control the segregated termination of entorhinal fibers, we compared immunolabeling for neurocan and chondroitin sulfate in sections from reeler and wild-type mice and found it similar in both genotypes. Together these results show that different mechanisms underlie the formation of commissural and entorhinal fiber layers during the development of the dentate gyrus.

Key words: hyaluronic acid; chondroitin sulfate proteoglycans; extracellular matrix; reeler mutant; axonal guidance; layer specificity; dentate gyrus

\section{Introduction}

The dentate gyrus is characterized by its laminated organization. The somata of the granule cells form the densely packed granular layer and extend their dendrites into the molecular layer. Fibers from the entorhinal cortex terminate in the outer molecular layer, whereas fibers from the ipsilateral and contralateral hippocampus innervate the inner molecular layer (Blackstad, 1956, 1958; Frotscher et al., 1988; Amaral and Witter, 1995). A sharp border segregates these two fiber projections. Although recent studies shed some light on the molecular and cellular factors involved in pathfinding of hippocampal afferents (Skutella and Nitsch, 2001), the determinants of the clear-cut segregation of these two projections have remained unknown.

Previous studies suggested that the lamination of entorhinal and commissural fibers forms by their sequential ingrowth during development (Bayer, 1980; Bayer and Altman, 1987); however, reversing this sequence in sequential cocultures did not alter this characteristic layer-specific termination (Frotscher and Heimrich, 1993). Recent studies have provided evidence that

Received Jan. 13, 2003; revised June 9, 2003; accepted June 11, 2003.

This study was supported by the Deutsche Forschungsgemeinschaft (SFB 505 and TR-3 to E.F. and M.F. and Fo 223/4-2 to E.F.), the European Commission (QLRT-30158), and by a Max Planck Research Award (M.F.). We thank Dr U. Rauch (Department of Experimental Pathology, Lund University, Lund, Sweden) for the NC-2 antiserum against neurocan.

*S.Z. and E.F. contributed equally to this study.

Correspondence should be addressed to Michael Frotscher, Institute of Anatomy, University of Freiburg, Albertstrasse 17, D-79104 Freiburg, Germany. E-mail: Michael.Frotscher@anat.uni-freiburg.de.

Copyright $\odot 2003$ Society for Neuroscience $\quad$ 0270-6474/03/237351-07\$15.00/0 early-generated Cajal-Retzius (CR) cells in the outer molecular layer guide the entorhinal fibers to the hippocampus and serve as transient targets (del Rio et al., 1997; Frotscher, 1998; Ceranik et al., 1999), keeping this projection in its appropriate termination zone. In fact, elimination of CR cells prevented the ingrowth of entorhinal afferents to the outer molecular layer (del Rio et al., 1997). With a similar concept, GABAergic interneurons in the inner molecular layer were assumed to be transient targets of commissural fibers (Borrell et al., 1999); however, in a mutant that lacks GABAergic interneurons in the hippocampus (Pleasure et al., 2000), the characteristic laminated termination of commissural fibers was preserved.

In addition to transient target neurons, membrane-bound molecules on granule cell dendrites and on the axons of the ingrowing afferents as well as extracellular matrix molecules may play a role in fiber segregation in the dentate gyrus. We have shown recently that the layer specificity of entorhinal afferents is lost by degradation of hyaluronan, an extracellular matrix (ECM) molecule (Förster et al., 2001). In the present study we demonstrate that degradation of hyaluronan specifically alters the entorhinal projection but leaves the commissural projection unaffected. In contrast, we show here that the laminar specificity of commissural fibers is altered when the tight packing of granule cells is lost, as happens to be the case in reeler mutant mice, indicating that the granule cells themselves carry a signal for the commissural fibers. In a triplet culture assay, commissural fibers from a wild-type culture form their normal compact projection 
to the inner molecular layer in cocultured wild-type dentate gyrus, but collaterals of the same commissural neurons are malpositioned in cocultured reeler dentate gyrus. Remarkably, malpositioning of the granule cells in reeler mice did not prevent the entorhinal fibers from forming a compact, sharply segregated fiber projection. Together these findings indicate that different mechanisms control the laminar specificity of entorhinal and commissural afferents to the dentate gyrus.

\section{Materials and Methods}

Preparation of hippocampal slice cultures. For the preparation of slice cultures, 0 - to 4-d-old mouse pups (wild-type and reeler mutants) were used. Reeler mice were identified by their well known morphological malformations in the cortex and hippocampus. The genotype of reeler mutants was confirmed by PCR analysis of genomic DNA, as described (Deller et al., 1999b). Brains were removed after decapitation under hypothermic anesthesia. All experiments were performed in agreement with the institutional guide for animal care. The hippocampi were dissected and sliced $(300 \mu \mathrm{m})$ perpendicular to their longitudinal axis with a McIlwain tissue chopper.

Preparation of hippocampal-hippocampal and entorhinohippocampal cocultures. For entorhinohippocampal cocultures, slices containing the hippocampus and the adjacent entorhinal cortex of newborn mouse pups (P0) were cultivated as static cultures for $12 \mathrm{~d}$ in vitro (DIV) (Stoppini et al., 1991). Slices were placed onto Millipore membranes and transferred to a six-well plate with $1 \mathrm{ml}$ of nutrition medium per well (25\% heat-inactivated horse serum, 25\% HBSS, 50\% minimal essential medium, 2 mм glutamine, $\mathrm{pH}$ 7.2). Cocultures of two or three hippocampal slices were used to study the formation of "commissural" connections. Wild-type to wild-type, wild-type to reeler, and reeler to wildtype cocultures were used. Slices were positioned in close vicinity to each other and incubated in $5 \% \mathrm{CO}_{2}$ at $37^{\circ} \mathrm{C}$. The medium was changed every $2 \mathrm{~d}$.

Hyaluronidase treatment of cocultures. Hyaluronidase (Calbiochem, San Diego, CA) was diluted in $0.9 \% \mathrm{NaCl}$ to concentrations ranging from 70 to 700 turbidity reducing units (TRU)/ml (Förster et al., 2001). Two microliters of the diluted hyaluronidase were applied directly to each individual coculture twice per day, beginning with the day of slice culture preparation until $10 \mathrm{DIV}$. Two microliters of $0.9 \% \mathrm{NaCl}$ without enzyme were added to control cultures.

Tracing of entorhinohippocampal fibers and hippocampal commissural fibers. After 10 DIV, a crystal of biocytin (Sigma, Munich, Germany) was placed on the entorhinal portion of the coculture or on the hilar region of one of two hippocampal cocultures to trace entorhinal and commissural projections to the dentate gyrus, respectively. In cocultures of different genotypes, projections either from wild type to reeler or from reeler to wild type were analyzed. After 12 DIV, the cultures were fixed with $4 \%$ paraformaldehyde, sectioned $(50 \mu \mathrm{m})$, and incubated with avidin-biotin-peroxidase complex (Vector Laboratories, Burlingame, CA). Sections were developed with diaminobenzidine/nickel and counterstained with cresyl violet.

Immunostaining for the hyaluronan-associated molecules neurocan and chondroitin sulfate. Four newborn reeler and three newborn wild-type mice were deeply anesthetized with an overdose of Nembutal $(300 \mathrm{mg} / \mathrm{kg}$ body weight) and transcardially perfused with $4 \%$ paraformaldehyde in $0.1 \mathrm{M}$ phosphate buffer $(\mathrm{PB})$. The brains were removed and postfixed for $24 \mathrm{hr}$ in $4 \%$ paraformaldehyde. Horizontal sections of the hippocampus were cut with a Vibratome $(50 \mu \mathrm{m})$. After incubation in $5 \%$ normal goat serum and $0.2 \%$ Triton $\mathrm{X}-100$ in $0.1 \mathrm{~m} \mathrm{~PB}$ for $1 \mathrm{hr}$ at room temperature, the sections were incubated in the following primary antibodies at $4^{\circ} \mathrm{C}$ for $2 \mathrm{~d}$ : rabbit polyclonal anti-Neurocan (NC-2) (1:5000; kindly provided by Dr. U. Rauch, Lund University, Lund, Sweden), mouse antichondroitin sulfate (CS-56) (1:500; Sigma). After they were rinsed several times in $0.1 \mathrm{M} \mathrm{PB}$, the sections were incubated in Cy3-conjugated goat anti-rabbit secondary antibody (for NC-2, 1:500) and Cy2conjugated donkey anti-mouse (for CS-56, 1:500), respectively, at $4^{\circ} \mathrm{C}$ overnight. Then the sections were rinsed with $0.1 \mathrm{M} \mathrm{PB}$ and mounted in Mowiol.

\section{Results}

\section{Laminar specificity of fiber projections to the dentate} molecular layer is maintained in slice cultures

Cocultures of entorhinal cortex and hippocampus confirmed that the formation of the laminar projection of entorhinal fibers to the outer molecular layer of the dentate gyrus is retained under these in vitro conditions (Fig. 1A,B) (Li et al., 1993; Frotscher and Heimrich, 1993; Frotscher et al., 1995; del Rio et al., 1997). Biocytin, injected into the entorhinal cortex of the culture, labeled many projection neurons in layers II and III of the entorhinal cortex, and the axons of these neurons could be traced to the entorhinal termination zones in the adjacent hippocampal portion of the culture. As clearly shown in Figure 1, $A$ and $B$, the entorhinal axons spared the inner molecular layer, the termination zone of commissural/associational fibers, by forming a sharp border. This clear-cut segregation of entorhinal fibers not entering the inner molecular layer was invariably seen in untreated control cultures $(n=16)$, despite some variability in the labeling of entorhinal axons. Similar results were obtained when not these complex cultures containing both entorhinal cortex and hippocampus in one section were used but individual slices of entorhinal cortex and hippocampus were cocultured (data not shown) (Frotscher and Heimrich, 1993).

When two hippocampal slices were cocultured and in one of them the hilar region was injected with biocytin to trace fiber connections between the two cultures, a different picture emerged. Under these conditions, fibers heavily labeled with biocytin populated the inner molecular layer bordering the granular layer (Fig. $2 A, B$ ). The inner molecular layer is the termination zone of commissural-associational fibers to the dentate gyrus (Blackstad, 1956), known to originate from hilar mossy cells (Frotscher et al., 1991; Amaral and Witter, 1995; Zappone and Sloviter, 2001). Accordingly, labeled fibers in the inner molecular layer after biocytin injection into the hilar area of a cocultured hippocampal slice were defined as commissural fibers in the present study. In these control cocultures, the commissural fibers regularly formed a compact projection to the inner molecular layer despite some variability in the amount of fibers labeled in individual tracer experiments $(n=14)$. In addition to this compact projection, a few fibers could regularly be traced to the outer molecular layer, probably representing the GABAergic commissural projection to the outer molecular layer described recently by Deller et al. (1995).

Labeled axons in the injected culture itself were regarded here as associational fibers. In fact, in the injected hippocampal culture, an associational projection to the inner molecular layer of the dentate gyrus and the mossy fiber projection to CA3 were stained (Fig. 2 A). Labeling of many mossy fibers, i.e., granule cell axons, is not surprising because they traverse the hilus, the site of tracer injection, on their way to the CA3 pyramidal cells. As in vivo, the mossy fiber projection was restricted to CA3 and did not invade the CA1 region (Fig. $2 \mathrm{~A}$ ). Together these data indicate that not only the signals for axonal pathfinding but also those for target layer recognition of entorhinal, commissural, and associational fibers were preserved in these cocultures.

\section{Hyaluronidase treatment abolishes laminar specificity of entorhinal fibers}

When entorhinohippocampal cocultures were treated with hyaluronidase, biocytin tracing confirmed that the laminar specificity of entorhinal fibers to the outer molecular layer is abolished by this treatment (Förster et al., 2001). The entorhinal axons no longer respect the border toward the inner molecular layer and 

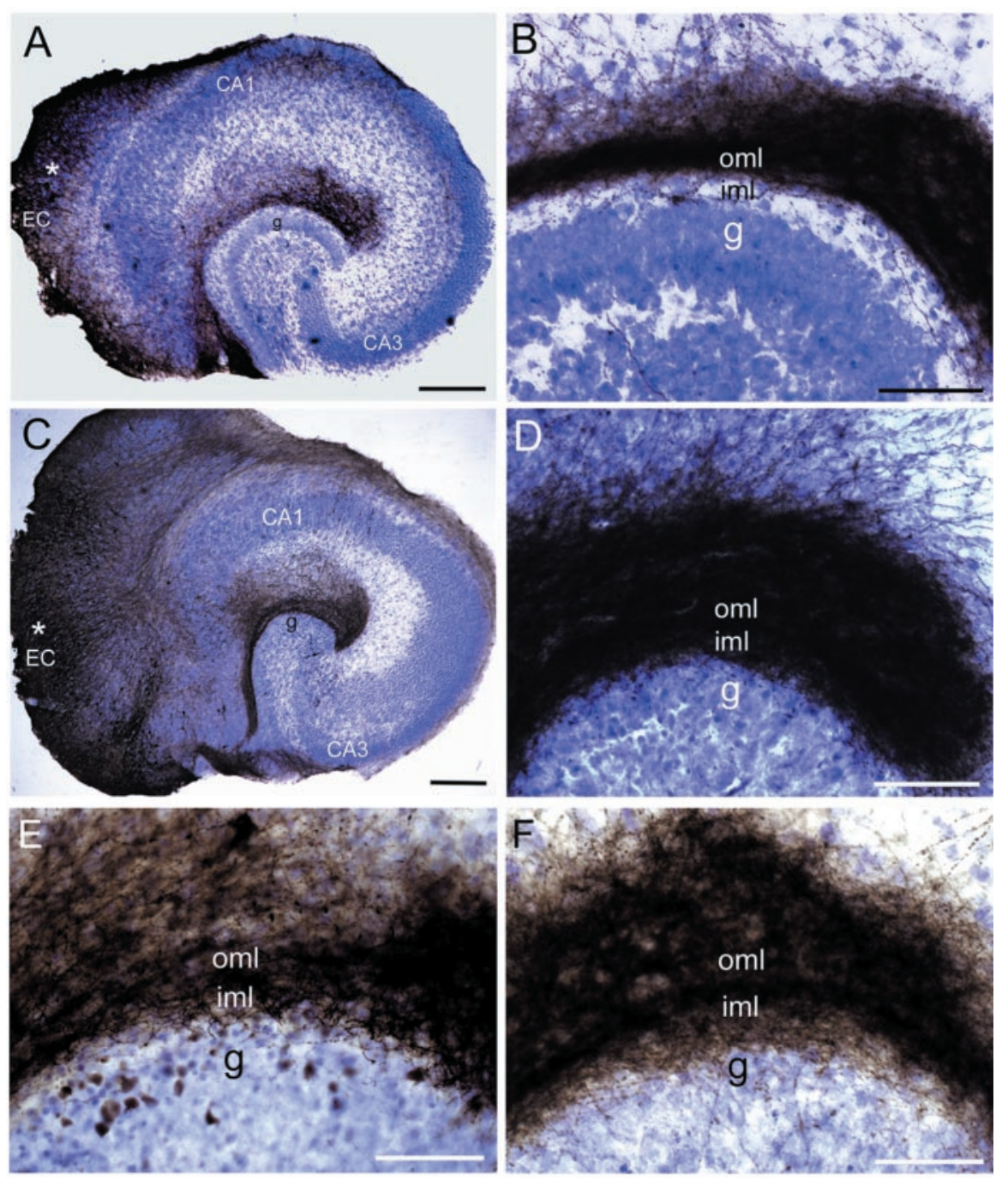

Figure 1. Hyaluronidase treatment disrupts lamina-specific growth of entorhinal fibers to the dentate outer molecular layer in entorhinohippocampal cocultures. $A, B$, Control: entorhinohippocampal cocultures incubated with medium not containing hyaluronidase. Entorhinal fibers (black) are visualized by tracing with biocytin. Asterisk marks injection site of tracer. Note that entorhinal fibers do not invade the inner molecular layer (iml) but are restricted to the dentate outer molecular layer (oml). $\mathrm{g}$, Granule cell layer; EC, entorhinal cortex. Hippocampal areas CA1 and CA3 are indicated. Scale bars: $A, 100 \mu \mathrm{m} ; B, 50 \mu \mathrm{m}$. C, D, Entorhinohippocampal coculture, treated with hyaluronidase for $10 \mathrm{DIV}$. Entorhinal fibers still project to the dentate molecular layer; however, they now invade the inner molecular layer and are no longer restricted to the outer molecular layer. Scale bars: $C$, $100 \mu \mathrm{m} ; D, 50 \mu \mathrm{m} . E, F$, Entorhinohippocampal cocultures treated with hyaluronidase in different concentrations: $70 \mathrm{TRU} / \mathrm{ml}(E)$ and $700 \mathrm{TRU} / \mathrm{ml}(F)$. Both low and high concentrations of hyaluronidase induce invasion of entorhinal fibers into the inner molecular layer, thus indicating the specificity of the enzyme treatment. Scale bars, $100 \mu \mathrm{m}$.

heavily innervate this zone, which is normally reserved for commissural-associational axons (Fig. $1 C, D)(n=30)$. The density of labeled entorhinal axons throughout the molecular layer varied between individual tracer experiments and different hyaluronidase concentrations up to $700 \mathrm{TRU} / \mathrm{ml}$ (Fig. $1 E, F$ ); however, ingrowth of entorhinal fibers into the inner molecular layer was already observed with the lowest enzyme concentration used (70 TRU/ml), suggesting that the effect was caused specifically by digestion of hyaluronan and not by residual protease activity in the enzyme preparation. We conclude that the entorhinal fibers found their way to the molecular layer but have lost their specificity for its outer part. The data point to a role of hyaluronan in the segregation of the entorhinal and commissural projection and indicate that proximal granule cell dendrites are ready to establish synaptic contacts with entorhinal fibers provided they were allowed to enter the inner molecular layer.
Hyaluronidase treatment does not affect laminar specificity of commissural fibers

We wondered whether hyaluronidase treatment would also abolish laminar specificity of commissural fibers to the dentate inner molecular layer. The same hyaluronidase treatment that disrupted laminar specificity of entorhinal fibers did not alter the laminated termination of commissural fibers in the inner molecular layer (Fig. $2 C, D)(n=36)$. Similarly, the projection of the mossy fibers was unchanged after hyaluronidase treatment (Fig. 2C). Thus, treatment with hyaluronidase did not cause an unspecific alteration of the tissue resulting in general changes in fiber ingrowth. Rather, the effect very specifically concerned the layer-specific termination of entorhinal afferents. The results indicate that molecules other than hyaluronan and molecules bound to it define the laminar specificity of commissural fibers.

\section{Laminar specificity of commissural fibers is determined by the position of granule cells}

To study a potential role of granule cell positioning for the layer-specific termination of both fiber systems, cocultures of wild-type and reeler mouse hippocampus were prepared. In reeler mutant mice, granule cells do not form a tightly packed layer but are loosely distributed throughout the hilar area (Stanfield and Cowan, 1979; Drakew et al., 2002). As a result of this migration defect, proximal and distal dendritic segments of neighboring granule cells are no longer co-aligned. When a wild-type hippocampal culture was cocultured with reeler mouse hippocampus, the commissural projection from the wildtype culture to the reeler culture was altered dramatically. The fibers no longer showed a segregated, laminated termination in the inner molecular layer but were loosely distributed throughout the hilar region like their target neurons, the granule cells (Fig. $3 A, B)(n=$ $40)$. In the wild-type culture, which was injected with the tracer, the associational fibers formed their typical compact projection to the inner molecular layer. Because both associational and commissural fibers originate from the same type of hippocampal neuron, these findings strongly suggest that positioning of the granule cells and hence membrane-bound molecules on granule cell somata and dendrites determine the layer specificity of hippocampal (associational and commissural) afferents to the dentate gyrus. This was confirmed in triplet culture experiments in which two wild-type hippocampal cultures were cocultivated with reeler hippocampus (Fig. $3 C-E$ ). In this choice situation, commissural fibers from a tracer-injected wild-type culture invaded both the other wild-type culture and the reeler culture, indicating that the signals attracting and guiding these fibers were 
present under both conditions; however, only in the wild-type culture did the commissural afferents form their characteristic compact band in the inner molecular layer (Fig. 3C,E). In contrast, in the reeler culture the fibers were distributed all over the hilar region (Fig. 3C,D). Because the fibers to both cultures emerged from the same cells of origin, these findings preclude the possibility that the loose termination of commissural fibers in the reeler mouse hippocampus is caused by a cellautonomous effect of the reeler mutation on the projecting cell itself. Rather, they suggest that the position of the target granule cell determines the commissural projection to the dentate gyrus. This conclusion was supported further by experiments in which commissural fibers from a reeler culture were traced to a wild-type culture of dentate gyrus. These commissural fibers from reeler hippocampus gave rise to a compact, layer-specific projection in the inner molecular layer of the wild-type dentate gyrus (Fig. $3 F, G)(n=18)$.

\section{Entorhinal fibers form a sharply} demarcated projection in reeler cultures As is known from tracer studies in reeler mice (del Rio et al., 1997; Deller et al., 1999a), the entorhinal fibers, unlike the commissural fibers, form a sharply demarcated projection to the molecular layer in these animals, likely because relevant molecules of the ECM such as hyaluronan and molecules bound to it are in place. In fact, immunostaining for the hyaluronanassociated molecules neurocan and chondroitin sulfate was similar in sections from wild-type and reeler dentate gyrus (Fig. 4A$D)$. As one would expect from these findings, cocultures of entorhinal cortex and hippocampus from reeler mice revealed the characteristic sharply segregated projection of entorhinal fibers to the molecular layer, precluding an essential role of reelin in pathfinding and target layer recognition of entorhinal afferents (Fig. 5A,B) $(n=65)$. This sharply demarcated projection of entorhinal fibers was lost, however, when the reeler hippocampal cultures were treated with hyaluronidase. This enzyme treatment resulted in a widespread distribution of entorhinal fibers throughout the molecular layer and hilus (Fig. 5C,D) $(n=80)$. These data are compatible with the notion that not granule cell positioning but components of the ECM, hyaluronic acid and associated molecules, determine the segregated termination of entorhinal fibers.

\section{Discussion}

We have shown that different mechanisms underlie the segregated layer-specific termination of entorhinal and commissural afferents to the dentate gyrus. By using a coculture approach in which the signals governing pathfinding of entorhinal afferents are preserved, we show that hyaluronan and molecules bound to it, such as chondroitin sulfate proteoglycans (Förster et al., 2001), are required to keep these fibers in the outer molecular layer. After treatment with hyaluronidase, the entorhinal fibers are no longer prevented from invading the inner molecular layer; how-
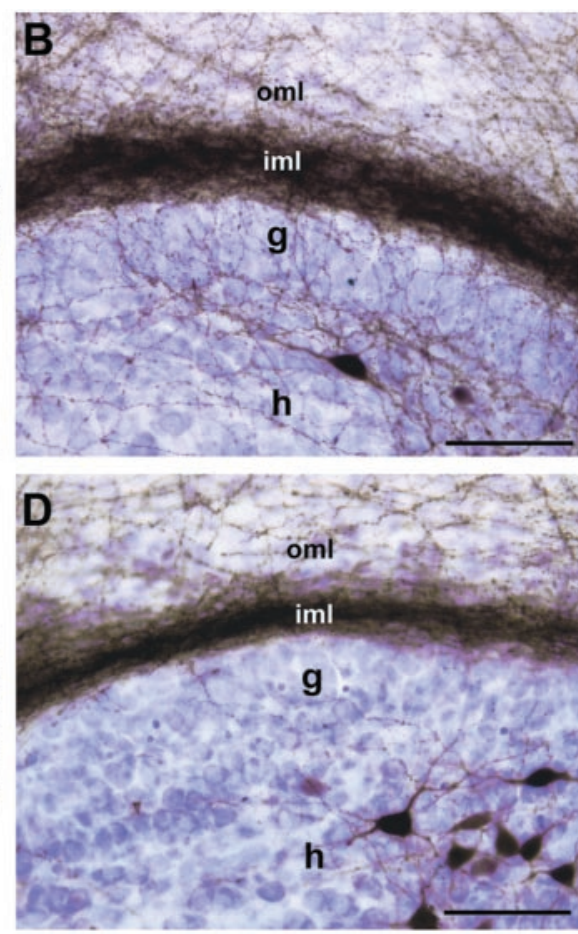

Figure 2. Hyaluronidase treatment does not affect laminar specificity of commissural fibers to the dentate inner molecular Scale bars: $A, 100 \mu \mathrm{m} ; B, 50 \mu \mathrm{m}$. C, D, Hippocampal coculture, treated with hyaluronidase for 10 DIV. Commissural fibers (black) are still restricted to the inner molecular layer. Note also that the mossy fiber projection (arrowhead) is not affected by the hyaluronidase treatment. The boxed area in $C$ is shown at higher magnification in $D$. Scale bars: $C, 100 \mu \mathrm{m} ; D, 50 \mu \mathrm{m}$.

ever, hyaluronidase treatment did not affect the laminar specificity of commissural fibers. Their layer-specific termination, but not that of the entorhinal fibers, was found to be dependent on the position of the target neurons.

\section{Laminar specificity of commissural fibers depends on granule cell positioning}

A comparison of neocortical and hippocampal organization suggests that the strictly segregated termination of hippocampal afferents results from the similarly rigid lamination of their target cells. Thus, the dense, parallel packing of pyramidal neurons and granule cells guarantees that identical dendritic segments of neighboring neurons run in parallel. The layered termination of afferents perpendicular to the ascending pyramidal and granule cell dendrites might then reflect a segregated, proximodistal distribution of different positional cues along the dendritic tree. The less rigid lamination of cell somata in the neocortex would be in favor of this hypothesis because it is accompanied by a more diffuse, overlapping termination of neocortical afferents when compared with afferent hippocampal projections.

The results of the present study indicate that positional cues on the target cell somatodendritic compartment may only account for the layer-specific termination of commissural fibers in the inner molecular layer of the dentate gyrus. The loose distribution and altered orientation of granule cells in the reeler mutant hippocampus is accompanied by a diffuse projection of commissural fibers. Along this line, recent comparative studies in reeler mice and in mutants lacking the reelin receptors apolipoprotein E receptor 2 (ApoER2) and very low density lipopro- 

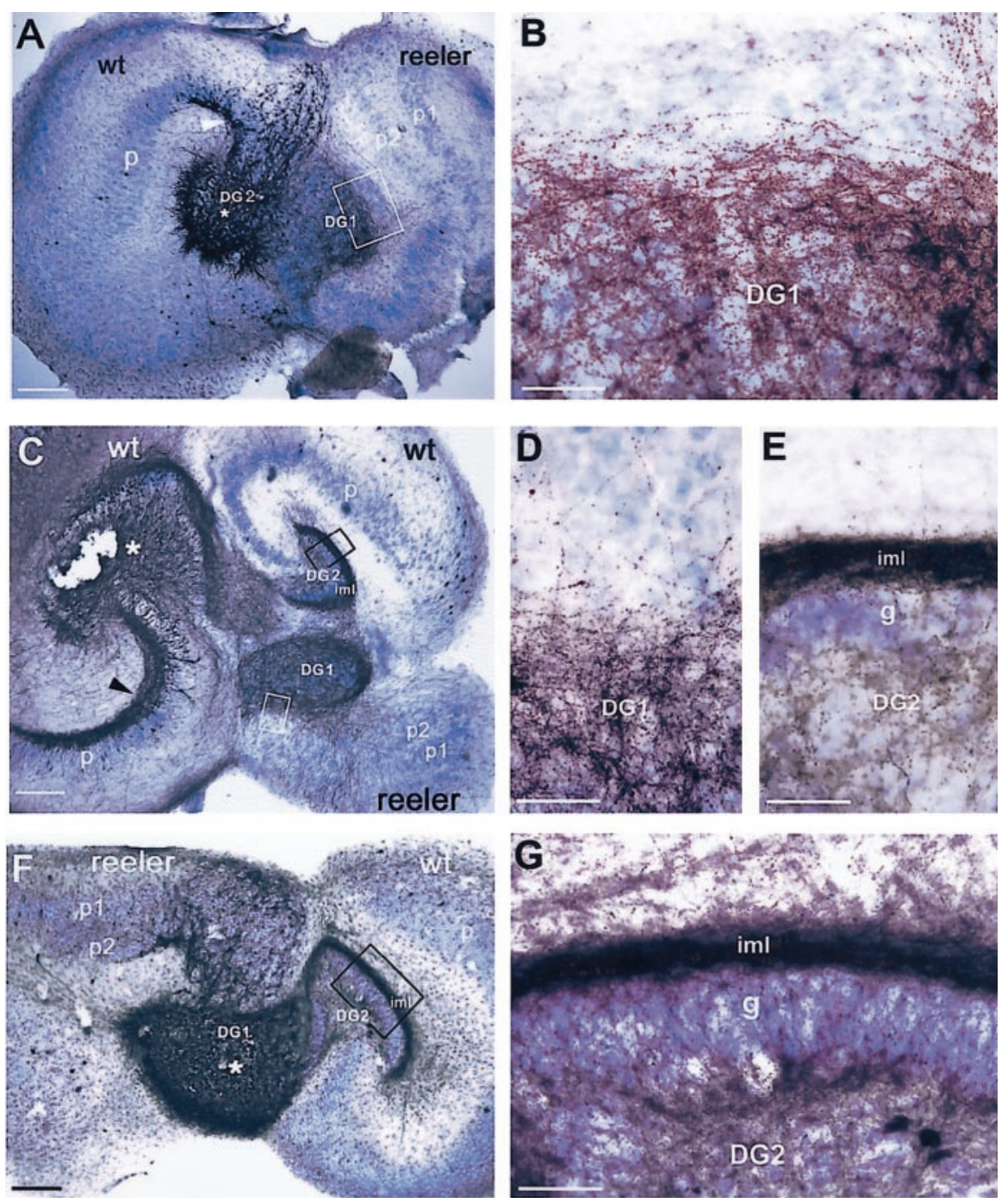

Figure 3. The trajectory of commissural fibers is determined by the position of the target granule cells. $A, B$, Cocultures of a wild-type (wt) hippocampal slice and a reeler mutant hippocampal slice. Commissural fibers projecting from the wild-type hippocampal slice to the reeler slice are visualized by tracing with biocytin; the injection site is marked by an asterisk. Note that commissural fibers do not form a sharp projection to the inner molecular layer of the reeler dentate gyrus (DG1) but intermingle with the malpositioned granule cells, suggesting that the trajectory of the commissural fibers is determined by the position of their target cells. As is characteristic for the reeler mutant, two pyramidal layers (p1, p2) are formed. Arrowhead points to the mossy fiber projection in the injected culture. $p$, Single pyramidal layer in the wild-type culture. The boxed area in $A$ is shown at higher magnification in $B$. Scale bars: $A, 100 \mu \mathrm{m} ; B, 50 \mu \mathrm{m}$. C $-E$, Triplet cocultures of two wild-type (wt) slices of hippocampus together with a reeler hippocampal slice. The biocytin injection site into one of the wild-type cultures is marked with an asterisk. Labeled commissural fibers invade the two other cultures, but only in the second wild-type culture do they show their characteristic compact termination in the inner molecular layer of the dentate gyrus (DG2). In the reeler hippocampal culture, the commissural fibers arising from the same cells of origin have lost their laminar specificity and terminate throughout the hilar region of the dentate gyrus (DG1). Arrowhead points to the mossy fiber projection in the injected culture. The boxed areas are shown at higher magnification in $D$ and $E$. Scale bars: $C, 100 \mu \mathrm{m} ; D, E, 50 \mu \mathrm{m}$. $F, G$, Coculture of reeler hippocampus and wild-type hippocampus. Biocytin was injected (asterisk) into the reeler dentate gyrus (DG1). Note that commissural fibers from the reeler dentate gyrus give rise to a compact projection to the inner molecular layer of the wild-type dentate gyrus (DG2). The boxed area in $F$ is shown at higher magnification in $G$. Scale bars: $F, 100 \mu \mathrm{m} ; G, 50 \mu \mathrm{m}$.

tein receptor (VLDLR) (Trommsdorff et al., 1999; Drakew et al., 2002; Gebhardt et al., 2002) have revealed a graded expression of the reeler phenotype in these animals. The severe malformation of the dentate gyrus in reeler was followed by a less pronounced granule cell dispersion in ApoER2-deficient mutants and by rather mild changes in dentate structure in VLDLR knock-out mice. The spread of the commissural projection clearly paralleled the extent of the granule cell migration defect in these mutants (Gebhardt et al., 2002). In agreement with the results of the present study, no such correlation was found for the entorhinal projection to the dentate gyrus; however, our present in vitro results are the first to prove that the aberrant commissural projection in the reeler dentate gyrus in fact is caused by malpositioning of the target granule cells and not by an altered growth capacity of the commissural neurons, a conclusion that could not be drawn from previous in vivo studies of fiber projections in the reeler hippocampus (Stanfield et al., 1979; Deller et al., 1999a,b; Gebhardt et al., 2002). Thus, commissural fibers from a wild-type culture formed an aberrant projection in a target culture from reeler hippocampus, and vice versa, commissural fibers from a reeler hippocampus gave rise to a normal compact projection to the inner molecular layer in the wild-type dentate gyrus.

\section{Hyaluronan and associated molecules determine the segregation of entorhinal fibers}

During the development of the hippocampal formation, the ingrowth of entorhinal fibers precedes that of commissural afferents. Although the former arrive as early as on embryonic day 17, the latter invade the dentate gyrus only postnatally (Supèr and Soriano, 1994; Ceranik et al., 1999). Arriving entorhinal afferents do not meet their proper target cells because the granule cells are mostly generated postnatally, after the arrival of entorhinal fibers in the outer molecular layer (Schlessinger et al., 1975; Bayer, 1980; Bayer and Altman, 1987). Moreover, at the time of entorhinal fiber ingrowth, even early-generated granule cells have not yet grown their dendrites as far as to the outer molecular layer (Lübbers and Frotscher 1988; Rihn and Claiborne, 1990). Thus, it appears unlikely that positional cues on distal granule cell dendrites attract and keep the entorhinal fibers in the outer molecular layer. Here we have shown that not signals on granule cell dendrites but hyaluronan in the extracellular matrix controls the segregated termination of entorhinal fibers in the outer molecular layer. These results are compatible with previous studies showing that lesioning or elimination of the granule cells did not alter the formation of a layer-specific entorhinodentate projection (Laurberg and Hjorth-Simonsen, 1977; Frotscher et al., 2001); however, pathfinding of entorhinodentate fibers was abolished by eliminating CR cells, the early-generated transient target cells of the entorhinal fibers (del Rio et al., 1997; Frotscher et al., 2001). Unlike the granule cells, CR cells in the outer molecular layer are present at the right time and in the right place to serve as targets for the early ingrowing entorhinal terminals. CR cells in the outer molecular layer have been shown to give rise to 
an early projection to the entorhinal cortex (Ceranik et al., 1999), providing a template for the outgrowing entorhinal axons, similar to the subplate cells for thalamocortical fibers (Gosh and Shatz, 1993). Like the subplate cells, CR cells are transient targets of ingrowing afferents, and most of them disappear during later postnatal life, when the definitive target neurons are available for synaptic contact. Like CR cells, subplate cells are present in reeler mice and give rise to an early corticothalamic projection providing the necessary template for the formation of thalamocortical projections (Molnar et al., 1998).

CR cells are present in reeler mice but do not secrete reelin. Thus, entorhinal axons can find their way to the dentate gyrus along the template of CR cell axons. Despite an abnormal composition of the extracellular matrix in reeler mice (Sheppard and Pearlman, 1997), entorhinal axons form a compact, clearly segregated projection in these mutants that is abolished, however, after degradation of hyaluronan (Fig. 5C,D). These findings clearly indicate that not the ECM molecule reelin but hyaluronan and molecules bound to it are essential for the segregation of entorhinal axons (Förster et al., 2001). This conclusion is compatible with the lack of significant differences between reeler and wild type in immunolabeling for neurocan and chondroitin sulfate, two hyaluronanassociated molecules (Fig. 4).

\section{Temporal coincidence of granule cell generation and commissural fiber ingrowth}

No transient target cells, such as CR cells for entorhinal axons, are required for the commissural fibers, which arrive late in development. Their late arrival coincides with the late generation of granule cells lasting far into the postnatal period (Schlessinger et al., 1975; Bayer and Altman, 1987). Here we have provided evidence that positional cues on the granule cells determine the distribution of commissural fibers. In the present triplet cultures (two wild-type hippocampal cultures plus one reeler culture), commissural axons from the biocytin-injected wild-type culture invaded the reeler culture where they were distributed as loosely as their target granule cells. In contrast, commissural fibers entering the other wild-type culture formed the characteristic compact band in the inner molecular layer. Because both projections originated from the same cells of origin (hilar mossy cells in the injected culture), the data imply that the abnormal commissural projection observed
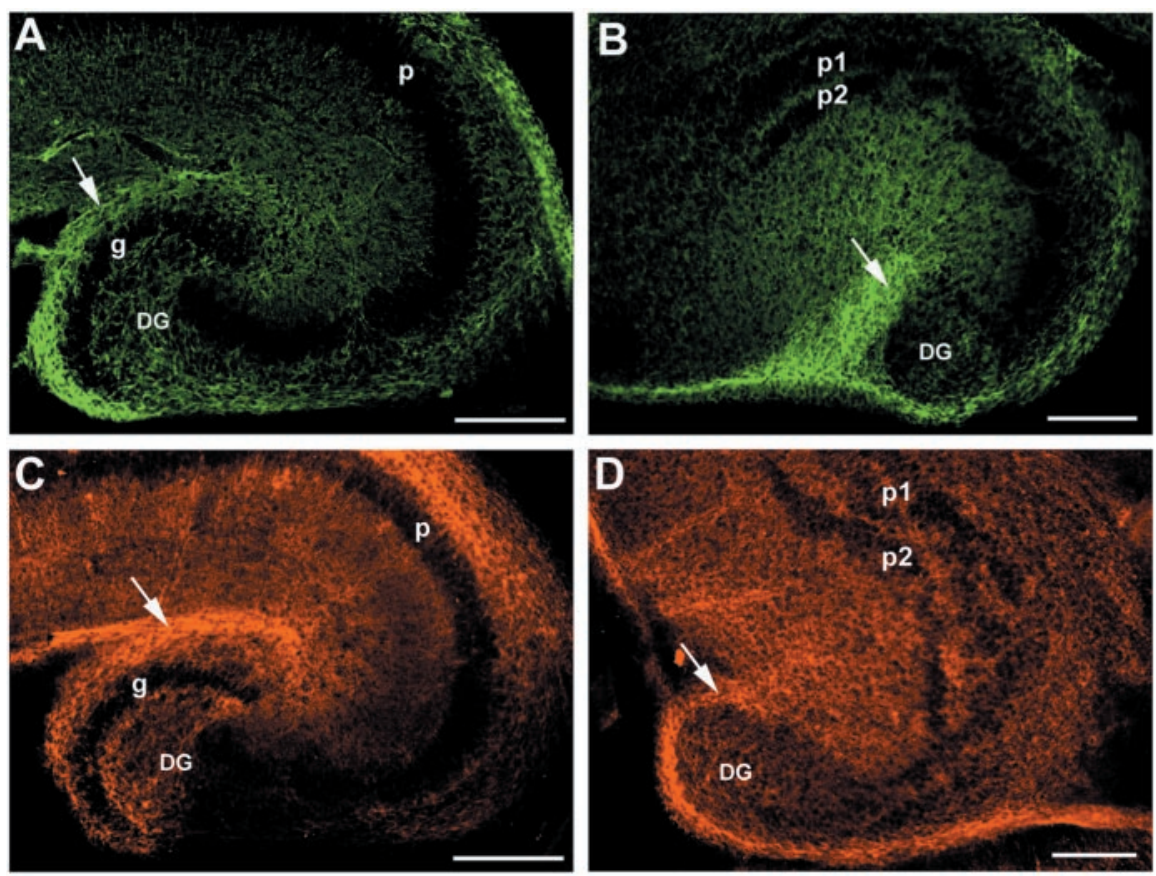

Figure 4. Immunostaining for the hyaluronan-associated molecules chondroitin sulfate and neurocan in the hippocampus of wild-type mice and reeler mutants. $A$, Immunostaining for chondroitin sulfate in the hippocampus of a wild-type mouse (PO). Note the strong staining in the dentate molecular layer (arrow). $B$, Immunostaining for chondroitin sulfate in the hippocampus of a reeler mutant (PO). Note that the intense staining of the molecular layer (arrow) is maintained. C, Neurocan immunostaining of the same section as shown in $A$. Note the intense labeling of the dentate molecular layer (arrow). D, Neurocan immunostaining of the same section from a reeler mutant as in $B$. The intense labeling of the dentate molecular layer (arrow) is similar as in C. Scale bars, $100 \mu \mathrm{m}$.
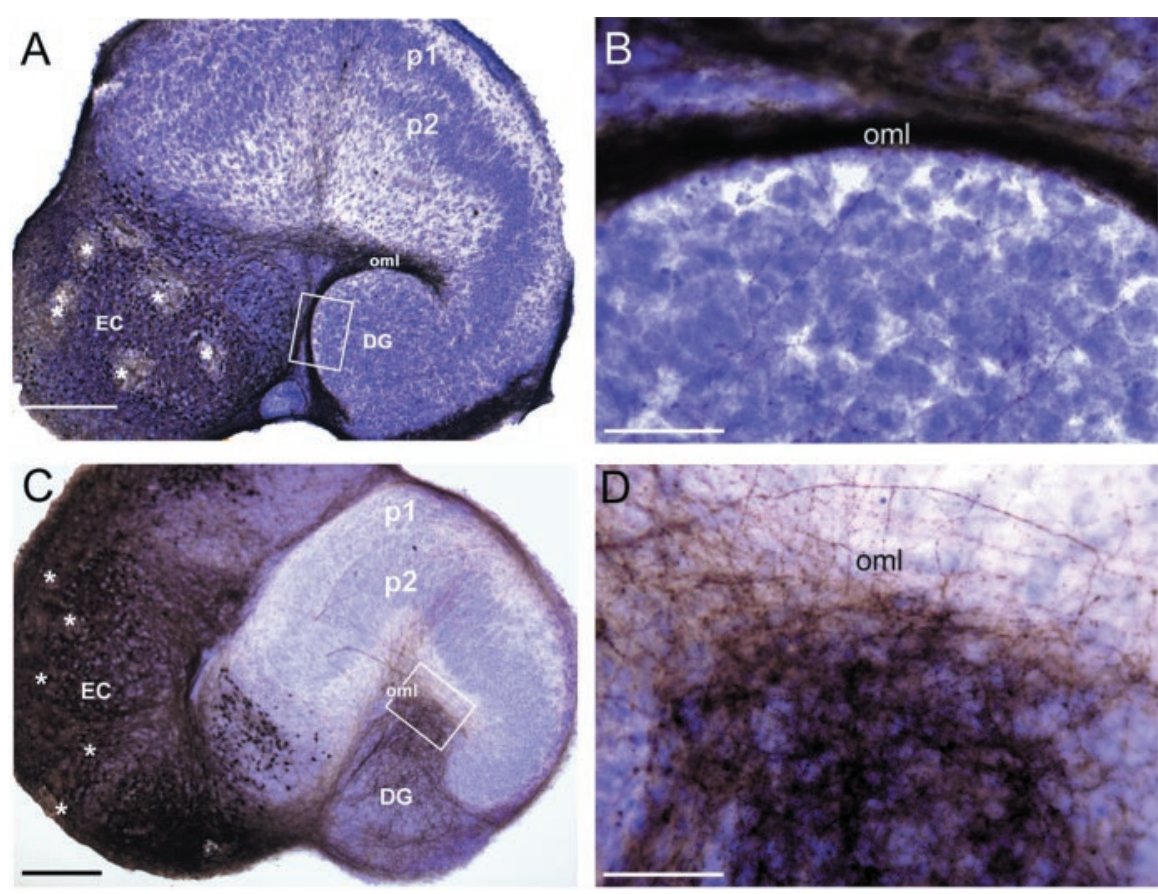

Figure 5. The trajectory of entorhinal fibers is not determined by the position of the target granule cells but by hyaluronidasesensitive molecules. $A, B$, Coculture of a reeler entorhinal cortex (EC) and hippocampus. Biocytin injection sites into the entorhinal cortex are marked with asterisks. Entorhinal fibers form a sharply segregated projection to the outer portion of the molecular layer (oml) of the dentate gyrus (DG) despite the malpositioned granule cells, demonstrating that the trajectory of entorhinal fibers is not influenced by the position of their target neurons. The boxed area in $A$ is shown at higher magnification in $B$. p1, p2, Two pyramidal layers in the reeler hippocampus. Scale bars: $A, 100 \mu \mathrm{m} ; B, 50 \mu \mathrm{m}$. C, D, Coculture of reeler entorhinal cortex (EC) and hippocampus treated with hyaluronidase for $10 \mathrm{~d}$. Note that the sharply segregated projection of entorhinal fibers is lost. The boxed area in C is shown at higher magnification in D. Scale bars: C, $100 \mu \mathrm{m} ; D, 50 \mu \mathrm{m}$. 
in reeler mice is not caused by aberrant pathfinding, defasciculation, or target recognition of the commissural fibers but in fact is caused by a migration defect of the granule cells carrying positional markers for commissural fibers. Accordingly, degradation of hyaluronan did not alter the distribution of the commissural fiber projection.

\section{References}

Amaral DG, Witter MP (1995) Hippocampal formation. In: The rat nervous system (Paxinos G, ed), pp 443-493. San Diego: Academic.

Bayer SA (1980) Development of the hippocampal region in the rat. I. Neurogenesis examined with ${ }^{3} \mathrm{H}$-thymidine autoradiography. J Comp Neurol 190:87-114.

Bayer SA, Altman J (1987) Directions in neurogenetic gradients and patterns of anatomical connections in the telencephalon. Prog Neurobiol 29:57-106.

Blackstad TW (1956) Commissural connections of the hippocampal region in the rat, with special reference to their mode of termination. J Comp Neurol 105:417-537.

Blackstad TW (1958) On the termination of some afferents to the hippocampus and fascia dentata: an experimental study in the rat. Acta Anat (Basel) 35:202-214.

Borrell V, Ruiz M, del Rio JA, Soriano E (1999) Development of the commissural connections in the hippocampus of reeler mice: evidence of an inhibitory influence of Cajal-Retzius cells. Exp Neurol 156:268-282.

Ceranik K, Deng J, Heimrich B, Lübke J, Shanting Z, Förster E, Frotscher M (1999) Hippocampal Cajal-Retzius cells project to the entorhinal cortex: retrograde tracing and intracellular labeling studies. Eur J Neurosci 11:4278-4290

Deller T, Nitsch R, Frotscher M (1995) Phaseolus vulgaris-leucoagglutinin tracing of commissural fibers to the rat dentate gyrus: evidence for a previously unknown commissural projection to the outer molecular layer. J Comp Neurol 352:55-68.

Deller T, Drakew A, Frotscher M (1999a) Different primary target cells are important for fiber lamination in the fascia dentata: a lesson from reeler mutant mice. Exp Neurol 156:239-253.

Deller T, Drakew A, Heimrich B, Förster E, Tielsch A, Frotscher M (1999b) The hippocampus of the reeler mutant mouse: fiber segregation in area CA1 depends on the position of the postsynaptic target cells. Exp Neurol 156:254-267.

del Rio JA, Heimrich B, Borrell V, Förster E, Drakew A, Alcantara S, Nakajima K, Miyata T, Ogawa M, Mikoshiba K, Derer P, Frotscher M, Soriano E (1997) A role for Cajal-Retzius cells and reelin in the development of hippocampal connections. Nature 385:70-74.

Drakew A, Deller T, Heimrich B, Gebhardt C, Del Turco D, Tielsch A, Förster E, Herz J, Frotscher M (2002) Dentate granule cells in reeler mutants and VLDLR and ApoER2 knockout mice. Exp Neurol 176:12-24.

Förster E, Zhao S, Frotscher M (2001) Hyaluronan-associated adhesive cues control fiber segregation in the hippocampus. Development 128:3029-3039.

Frotscher M (1998) Cajal-Retzius cells, reelin, and the formation of layers. Curr Opin Neurobiol 8:570-575.

Frotscher M, Heimrich B (1993) Formation of layer-specific fiber projections to the hippocampus in vitro. Proc Natl Acad Sci USA 90:10400-10403.

Frotscher M, Kugler P, Misgeld U, Zilles K (1988) Neurotransmission in the hippocampus. Advances in anatomy, embryology and cell biology, Vol 111. Berlin: Springer.

Frotscher M, Seress L, Schwerdtfeger WK, Buhl E (1991) The mossy cells of the fascia dentata: a comparative study of their fine structure and synaptic connections in rodents and primates. J Comp Neurol 312:145-163.
Frotscher M, Zafirow S, Heimrich B (1995) Development of identified neuronal types and of specific synaptic connections in slice cultures of rat hippocampus. Prog Neurobiol 45:143-164.

Frotscher M, Seress L, Abraham H, Heimrich B (2001) Early generated Cajal-Retzius cells have different functions in cortical development. In: Brain stem cells (Miyan J, Thorndyke M, Beesley PW, Bannister C, eds), pp 43-49. Oxford: BIOS.

Gebhardt C, del Turco D, Drakew A, Tielsch A, Herz J, Frotscher M, Deller T (2002) Abnormal positioning of granule cells alters afferent fiber distribution in the mouse fascia dentata: morphologic evidence from reeler, apolipoprotein E receptor 2-, and very low density lipoprotein receptor knockout mice. J Comp Neurol 445:278-292.

Gosh A, Shatz C (1993) A role for subplate neurons in the patterning of connections from thalamus to neocortex. Development 117:1031-1047.

Laurberg S, Hjorth-Simonsen A (1977) Growing central axons deprived of normal target neurones by neonatal X-ray irradiation still terminate in a precisely laminated fashion. Nature 269:158-160.

Li D, Field PM, Starega U, Li Y, Raisman G (1993) Entorhinal axons project to dentate gyrus in organotypic slice co-culture. Neuroscience $52: 799-813$.

Lübbers K, Frotscher M (1988) Differentiation of granule cells in relation to GABAergic neurons in the rat fascia dentate. Combined Golgi/EM and immunocytochemical studies. Anat Embryol 178:119-127.

Molnar Z, Adams R, Goffinet AM, Blakemore C (1998) The role of the first postmitotic cortical cells in the development of thalamocortical innervation in the reeler mouse. J Neurosci 18:5746-5765.

Pleasure SJ, Anderson S, Hevner R, Bagri A, Marin O, Lowenstein DH, Rubenstein JLR (2000) Cell migration from the ganglionic eminences is required for the development of hippocampal GABAergic interneurons. Neuron 28:727-740.

Rihn LL, Claiborne BJ (1990) Dendritic growth and regression in rat dentate granule cells during late postnatal development. Dev Brain Res 54:115-124.

Schlessinger AR, Cowan WM, Gottlieb DI (1975) An autoradiographic study of the time of origin and the pattern of granule cell migration in the dentate gyrus of the rat. J Comp Neurol 159:149-176.

Sheppard AM, Pearlman AL (1997) Abnormal reorganization of preplate neurons and their associated extracellular matrix: an early manifestation of altered neocortical development in the reeler mutant mouse. J Comp Neurol 378:173-179.

Skutella T, Nitsch R (2001) New molecules for hippocampal development. Trends Neurosci 24:107-113.

Stanfield BB, Cowan WM (1979) The morphology of the hippocampus and dentate gyrus in normal and reeler mice. J Comp Neurol 185:393-422.

Stanfield BB, Caviness Jr VS, Cowan WM (1979) The organization of certain afferents to the hippocampus and dentate gyrus in normal and reeler mice. J Comp Neurol 185:461-483.

Stoppini L, Buchs PA, Muller D (1991) A simple method for organotypic cultures of nervous tissue. J Neurosci Methods 37:173-182.

Supèr H, Soriano E (1994) The organization of the embryonic and early postnatal murine hippocampus. II. Development of entorhinal, commissural and septal connections studied with the lipophilic tracer DiI. J Comp Neurol 344:101-120.

Trommsdorff M, Gotthardt M, Hiesberger T, Shelton J, Stockinger W, Nimpf J, Hammer RE, Richardson JA, Herz J (1999) Reeler/disabled-like disruption of neuronal migration in knockout mice lacking the VLDL receptor and ApoE receptor. Cell 97:689-701.

Zappone CA, Sloviter RS (2001) Commissurally projecting inhibitory interneurons of the rat hippocampal dentate gyrus: a colocalization study of neuronal markers and the retrograde tracer Fluoro-gold. J Comp Neurol 441:324-344. 